\author{
Jurij Tureha (D)
}

Ivan Franko Lviv National University

\title{
BIECZ - BRODY - BILA CERKVA: TRADE CONTACTS AGAINST THE BACKDROP OF EVERYDAY LIFE IN THE SEVENTEENTH CENTURY
}

\begin{abstract}
This study examines the report of the death of the Jewish merchant Rubin Josefowicz (9.02.1663). This study uses the report to fulfil three goals. First, it sheds light on Brody's Jewish past. A copy of documents from the town of Biecz is for the moment the earliest complete source which describes in detail the trade activity of a Jew from Brody. Secondly, the report reveals additional evidence of the trade history within the borders of the Polish-Lithuanian Commonwealth. Finally, the investigation reveals aspects of merchants' everyday life in the town of the Carpathian foothill region.
\end{abstract}

Key words: Biecz, Brody, Bila Cerkva, trade, Jews, everyday life

Słowa kluczowe: Biecz, Brody, Biała Cerkiew, handel, Żydzi, życie codzienne

\section{A Short Preface to the Source Text}

The town of Brody in the nineteenth century was a well-known hub of Jewish trade and a centre of Hebrew science and civilisation'. Unofficially, the town was called a 'Galician Jerusalem', a well-deserved nickname given that many Jews settled there ${ }^{2}$. Among the various occupations favoured by Brody's Hebrews, trade featured prominently. Despite this,

Franciszek Jaworski, 'Brody', Tydzień: Dodatek literacko-naukowy “Kuriera Lwowskiego”(15 lutego 1903).

2 For example, in 1765, the number of Jews in Brody was higher than in Lviv, Krakow or Wilno. See Dawid Wurm, Z dziejów żydostwa Brodzkiego za czasów dawnej Rzeczypospolitej Polskiej (do r. 1772) (Brody: Z drukarni Pitscha i Weinstocka, 1935), 2. 
however, our knowledge of their involvement in the town's commercial life is scanty, especially for the $17^{\text {th }}$ century.

Research conducted for this study in the magistrate archive has revealed that Jews were an important part of Brody's community as early as the first decade of the town's existence ${ }^{3}$. This finding supports Dawid Wurm's thesis that three indigenous nations constituted Brody's population since its foundation ${ }^{4}$. Among these first residents, trade was a major occupation. Indeed, records dating from 1590 show that Jews from Brody participated in the commercial life of Eastern Europe. That year Izraelko, the son of Boroch, „....odiachal na kupią do Woloch." The pages of Brody's magistrate books offer such glimpses of this trade activity from 1590 through the first half of the seventeenth century. Unfortunately, much of this evidence is fragmentary, brief and lacking in detail.

The first thorough account concerning a Hebrew from Brody who was engaged in commerce is the report of an investigation into the death of Rubin Josefowicz. Written in 1663 , the report is a unique primary document that is significant for several reasons. Not only does it provide rare insight into Brody's past, but the report also advances Ukrainian research on trade and everyday life in the Early Modern period. The tendency among historians has been to frame that history in broad, general terms, resulting in studies that only cursorily address topics such as everyday life, trade, and even the development of towns and cities in Early Modern Ukraine. ${ }^{6}$ These circumstances have arisen due to several reasons, but the most important one seems to be the complicated and quite fragmentary archival evidence, a source base which is probably daunting for Ukrainian historians who study the $16^{\text {th }}-18^{\text {th }}$ centuries. Finally, we believe that the report deserves to be published because a small number of personal documents, such as diaries or letters, created by ordinary, common Eastern Europeans, makes every source, which contains evidence about daily activities of traders, precious from a historical standpoint.

One more thing that needs to be pointed out is that Rubin's death investigation presents a case of trade activity by merchants from modern central Ukraine in relatively small

3 The founder of the town Stanisław Żółkiewski received a foundation charter from King Stefan Batory in 1584 .

4 Dawid Wurm, $Z$ dziejów żydostwa Brodzkiego za czasów dawnej Rzeczypospolitej Polskiej..., op. cit., 4.

5 CSHAU in Lviv city. Collection 24. Inventory 1. Folder 1. P. 31-31v.

6 Fortunately, the first steps on this path have already been taken, and great collections of sources have been published. See Volodimir Kravčenko, Nataliâ Âkovenko, Torbivlâ na Ukraïni XIV - ser. XVII st.: Volińn i Naddniprânsinina (Kiïv: Naukova Dumka, 1990). Ukraïnśke povsâkdennâ ranńomodernoï dobi: zbìrnik dokumentiv, ed. Irina Vorončuk, Vipusk 1, Volin 16 st. (Kiïv: Feniks, 2014). Two other collected volumes have also been dedicated to the history of everyday life in Early Modern Ukraine, but the issues connected with merchants were omitted there. See Povsâkdennâ ranńomodernoï Ukraïni, ed. Viktor Horobeć, tom 1, Praktiki, kazusi ta deviaciï povsâkdennâ (Kiïv: İnstitut İstorii Ukraïni NAN Ukraïni, 2012). Povsâkdennâ rannomodernoï Ukraïni, tom 2, Svit rečej i povsâkdennih uâvleń, ed. Viktor Horobeć (Kï̈: İnstitut İstoriï Ukraïni NAN Ukraïni, 2013). Cyrillic graphemes have been transliterated according to the table given in the paragraph 318 of Zasady pisowni i interpunkcji. 
towns of modern southern Poland. For example, we could not find any evidence that proved the contacts with Biecz or Krosno in a significant collection of sources dedicated to the trade history of Volyn and central Ukraine regions until the mid- $17^{\text {th }}$ century ${ }^{7}$. In light of this, the published source enlarges our knowledge about trade contacts with the towns of Polish foothills.

The document that is the focus of this study is kept in collection no. 24, file no. 13 of the Central State Historical Archive of Ukraine in Lviv. This collection includes 65 books of Brody's magistrate on more than 8000 leaves. In comparison with Lviv's magistrate collection, these numbers are definitely small, but in contrast to other Ukrainian private town' magistrate archives, it forms a good source base for the research in the sphere of urban, social and economic history of Early Modern Ukraine.

The published document consists of three parts. The first and largest one is the investigation into Rubin Josefowicz's death, which was conducted at the request of the merchant Iwan Boyko. It contains statements of witnesses, who were citizens and dwellers of Biecz, given on Monday, the $12^{\text {th }}$ of February 1663. The content of their stories covers the events which took place from Thursday, the $8^{\text {th }}$, to Sunday, the $11^{\text {th }}$ of February. All accounts were signed by Biecz's scribe Petri Eibielgowicz, sealed and issued to the applicant (Boyko). The second part includes the testimony of an official from the local castle stating that Josefowicz died a non-violent death. It was recorded the same day as the first part and signed by the castle's judge and scribe. In the third part, written in the town of Brody on the $26^{\text {th }}$ of February, Rubin's relatives officially renounced any claims against Iwan Boyko. As the initiator of the investigation, Boyko was driven by the fear of possible problems that Rubin's relatives could cause him in the future, and so, to be on the safe side, he entered a copy of the case to Brody's magistrate book. We do not know exactly who rewrote it in Brody, but at the time the town's official scribe was Andrzey Strupieszowsky ${ }^{8}$. Though the scabini book of the town of Biecz for the years 1662-1677 survived, at present the entry dated the $12^{\text {th }}$ of February is missing. There is also a wide gap in the entries for the months from February up to July 1663 in the abovementioned book. Nowadays the archive of Biecz's magistrate is in the custody of $\mathrm{Krakow}^{10}$. All three parts of the document take up a total of eight and a half leaves, which are app. $16 \times 20 \mathrm{~cm}$ in size. The majority of investigation's text was written in Polish; however, some small standard parts were drawn up in Latin.

In this preface, we will refrain from elaborating on the precise content of the document because its full text is given below. However, some of the most prominent features

\footnotetext{
7 Volodimir Kravčenko, Nataliâ Âkovenko, Torhivlâ na Ukraïni XIV - ser. XVII st.: Voliń i Naddniprânsinina, op. cit.

8 CSHAU in Lviv. Collection 24. Inventory 1. Folder 13. P. 326v., Folder 33. P.14.

9 We express our sincere gratitude to Wiesław Filipczyk, a member of the National Archive in Cracow, who helped us to determine this fact.

10 Archiwum Narodowe w Krakowie. Collection 29/101/0. File 18 (Księga ławnicza biecka, 1662-1677).
} 
should be highlighted. First of all, the presented source provides us with an interesting case of everyday life experiences of traders in the Early Modern Polish-Lithuanian Commonwealth, which is intertwined with the stories of Biecz's population. For example, during the investigation into Rubin's death, one witness mentioned a theatrical play that was staged in the town before the start of Lent. The published source also depicts merchants from the territory of modern Ukraine trading with towns in the region at the foot of the Carpathian Mountains of contemporary Poland. The source also provides us with an opportunity to look more closely at the culture of alcohol consumption and its place in the society as well as prevailing attitudes towards spirits. The investigation into Rubin's death also shows us the spread of vivid language among the common folk. For instance, one of the eyewitnesses described the appearance of the dying Jew, using the phrase "as white as chalk". Although we doubt whether the document contributes some new significant information to the well-researched history of Biecz ${ }^{11}$; nonetheless, it is undoubtedly interesting and important historical evidence for the past of Brody or Bila Cerkva.

Preparation and translation of the source adheres to the rules provided by Kazimierz Lepszy $^{12}$. For example, we have omitted from the Latin translations the sections which stated that a witness was summoned to the court at Iwan Boyko's request, that they took the oath according to his/her social position, and that they gave testimony. The standard endings of each witness story, which confirmed that written evidence matched its oral counterpart, were also omitted. Apart from these, Latin words, which were shortened in the original text, are written out without using square brackets in the published one (e.g. dca $\rightarrow$ dominica, prxa $\rightarrow$ proxima et al.). The spelling of almost all words including the names of settlements was updated according to the rules of modern Polish. The most common substitutions were the following: $a \rightarrow e, i \rightarrow j, n \rightarrow n$, $o \rightarrow o ́, s \rightarrow \dot{s}, y \rightarrow i / j, z \rightarrow \dot{z}$. In the original text the letter «y» was used as a conjunction, so it was replaced by the letter «i Letter capitalization and punctuation were normalised as well. In several places, commas were substituted by full stops in order to truncate enormously large original sentences. In contrast to the abovementioned modernisations of the text's language, people's names were left as in the manuscript.

11 A special contribution to the research of Biecz's past was made by Tadeusz Ślawski. See Tadeusz Ślawski, Biecz i Gorlice: ośrodki handlu winem od XIV w. do XVIII w. (Biecz: Towarzystwo Kulturalne Biecza i Regionu im. Marcina Kromera, 2001). Tadeusz Ślawski, Produkcja i wymiana towarowa Biecza w XVI i XVII wieku (Rzeszów: Towarzystwo Przyjaciół Nauk w Przemyślu, 1968). Tadeusz Ślawski, 'Studia nad ludnością Biecza w wiekach XVI-XVII’, Matopolskie Studia Historyczne 1, zeszyt 3-4 (1958), 21-66.

12 Kazimierz Lepszy, Instrukcja wydawnicza dla źródet historycznych od XVI do potowy XIX wieku (Wrocław: Zakład im. Ossolińskich, 1953). 


\section{List of abbreviations}

CSHAU - Central State Historical Archive of Ukraine in Lviv

JKM - Jego Królewska Mość

JMP - Jego Mość Pan

JW $\quad-$ Jaśnie Wielmożny

WMc - Wasz Mość

\section{List of persons mentioned in the document}

Albertus Kędziersky

Albertus / Woyciech Piecek / Pieczek

Albertus Pieczek

Casimiro Okleysky

Chyl Moszkowicz

Iwachowsky

Dorotha

Grzegorz

Haedviga

Hesterka

Ioannes / Iwan / Iwani Boyko

Iwan Greczyn

Jan Baptysta

Jan baptised Jew

JMP Constanty

Josef Lewkowicz

Leszczynska

Martinus Kozik

Olszowska

Pan Bakałarz

Petri Eibielgowicz

Pląszowska / Pleszewska

Wielogłowsky

Rubin Josefowicz / Jozefowicz / Jozephowicz

Simon Stenclowicz

Valentini / Walenty Mołtaga z Skalmierza

Valentinus Kozdry a consul of Biecz

a consul of Biecz and a brother to Albertus Pieczek, a whitewasher

a citizen of Biecz, a whitewasher and a master of bleachery

advocatus of Brody

a citizen of Brody, a relative of Hesterka

a member of Biecz's castle government

Simonis Stenclowicz's wife

Biecz's guest from Wieliczka

a wife of Christophor Bielanowicz, a local whitewasher

Rubin Josefowicz's wife

a citizen of Bila Cerkva

presumably another name of Iwan Boyko

a guest in the home of consul Albertus Pieczek

a dweller of Kanczuga

Konstanty Jacek Lubomirski

a relative of Hesterka

a dweller of Biecz

a headmaster of butchers in Biecz

a dweller of Biecz

a dweller of Biecz

a scribe of Biecz

a dweller of Biecz

a judge and subprefect of Biecz's castle

a Jew, a dweller of Brody

a charioteer at the bleachery of Biecz

a member of Biecz's castle government (woźny)

a headmaster of the guild of tailors in Biecz 
List of places mentioned in the document

\begin{tabular}{|c|c|c|}
\hline Name in the source & Modern name & Location \\
\hline Biała Cerkwa (town) & Bila Cerkva & $\approx 703 \mathrm{~km}$ to the east of Biecz \\
\hline Biecz (town) & Biecz & $\approx 120 \mathrm{~km}$ to the south of Kraków \\
\hline Brody (town) & Brody & $\approx 325 \mathrm{~km}$ to the east of Biecz \\
\hline Jasło (town) & Jasło & $\approx 18 \mathrm{~km}$ to the east of Biecz \\
\hline Kanczuga (town) & Kańczuga & $\approx 110 \mathrm{~km}$ to the NE of Biecz \\
\hline Krosno (town) & Krosno & $\approx 44 \mathrm{~km}$ to the east of Biecz \\
\hline Lisowsk (town) & Lisów & $\approx 7 \mathrm{~km}$ to the NE of Biecz \\
\hline Podgorze & Podgórze & $\begin{array}{l}\text { a region in Poland where Biecz } \\
\text { and Krosno are located }\end{array}$ \\
\hline Serwaniec / Serwoniec (inn) & - & $\begin{array}{l}\text { in the document, the location is } \\
\text { described as "...nad Boczalą" }\end{array}$ \\
\hline Siepietnica / Szepietnica (village) & Siepietnica & $\approx 3,5 \mathrm{~km}$ to the $\mathrm{NE}$ of Biecz \\
\hline Skalmierz (village) & Skalmierz & $\approx 340 \mathrm{~km}$ to the NW of Biecz \\
\hline Wieliczka (town) & Wieliczka & $\approx 110 \mathrm{~km}$ to the west of Biecz \\
\hline
\end{tabular}

\section{The Investigation into Rubin Josefowicz's death}

Biecz, 12 II 1663, Brody 26 II 1663

[266v] Iwan Boyko z Białej Cerkwi

Actum feria secunda post dominicam Oculi Quadragesimalem Anno Domini Millesimo sexcentesimo sexagesimo tertio ${ }^{13}$.

Coram famato Casimiro Okleysky advocato comparens personaliter famatus Ioannes Boyko civis Białocerkieviensis commonstravit inquisitionem authenticam ex actis scabinalibus Biecensibus extraditam et sigillo eiusdem civitatis roboratam cum subscriptione Petri Eibielgowicz notarii iurati petens illam actis praesentibus inseri cuius inquisitionis tenor ut sequitur talis est.

Judicium necessarium bannitum feria secunda post dominicam Invocavit Quadragesimalem proxima die duodecim Februarii Anno Domini Millesimo sexcentesimo sexagesimo tertio.

13 26th of February 1663. 
Stanąwszy przed urzędem i aktami niniejszymi ławniczymi bieckimi, sławny pan Iwan Boyko z Miasta JKM Białej Cerkwie, starostwa i posesji JW JMP Konstantego hrabie na [267] Wiśniczu i Jarosławiu, podczaszego koronnego, sądeckiego etc. etc. s[t]arosty oświadczył się temuż urzędowi. I prosił w tej mierze o wysłuchanie inkwizycji, jako niewierny niegdyś Rubin Josefowicz Żyd i obywatel miasta Brodów, który z pomienionym panem Iwanem Boykiem, gdy tu w Podgórze czasu niedawnego, to jest we środę, przed nowym latem polskim z domu swego z Białej Cerkwie przez Brody dla płócien jechał, nieproszony na usługę jego wparł się i o koszcie jego w Podgórze przyjechawszy, w Krośnie kilka sztuczek płótna na swą potrzebę kupił, a pomieniony Iwan, iż wedle potrzeby swojej tam nic kupić nie mógł, tu do Biecza brał się. Wiedząc, iż w Bieczu Żyd jednego dnia mieszkać dla przywilejów, które z dawna mają, mieszkać nie może, aby był w Krośnie został perswadował i prosił, i co by tam był w Krośnie strawił wrócić i zapłacić obiecywał. On znajomościami z niektórymi mieszczanami bieckimi szczycąc się, asekurował tegoż Iwana, że bezpieczne mógł tu conversować y onemu służyć, i tak z tymże Iwanem do Biecza przyjechał nieproszony, jednak za usługi umówione ukontentowany. A gdy w pią- [267v] tek blisko przeszły, płócien nakupiwszy i zapłaciwszy, a na komorach JKM odprawiwszy, z Biecza z tymże Iwanem w drogę jechać mieli, i tego Żyda upraszał, aby z nimi wespół przy towarze jechał i niczym się nie zabawiał. On, tłumoczek i skrzynkę na jego wóz włożywszy, powiedział: "Jedźcie wy mimo miasto, a ja wam zabieżę na gościniec przez miasto". Czekał go tedy u murowanego mostu za bramą niżną biecką w tenże piątek do samego niemal wieczora, jako się to ze świadectw pokaże, a nie mogąc się doczekać, szedł na blech biecki, dowiadując się, co się z tym Żydem dzieje. Zastał go śpiącego, w izbie ciepłej leżącego, bardzo chrapiącego, kędy czeladź blichowa mieszka. Budził go, żadną miarą nie mógł go obudzić. I drugi raz w godzinę przyszedł, także zastał leżącego, bardzo chrapiącego. Chciał go na kolasę wziąć, ale to rzecz była niepodobna tak zapamiętałego, ani o sobie czującego, dźwigać i wozić. Tak tedy śpiący został na blechu, a z towarem swoim z miejsca, na którym go czekał, musiał się ruszyć, gdyż noc następowała i niebezpiecznie było na tym miejscu stać i dla koni, i dla towaru. Nie mogąc dostać gospody na przedmieściu bieckim i [268] w Szepietnicy, która graniczy z przedmieściem bieckim, musiał zaraz z wielkim niebezpieczeństwem swoim jechać do karczmy, którą Serwancem zowią nad Boczalą, w której czekał przez całą sobotę i wczoraj, rozumiejąc, że w sobotę szabas miał odprawować pod Bieczem. Dowiedziawszy się tedy od pewnych osób (od Jana Żyda ochrzczonego, który mieszka w Kańczudze) w sobotę przeszłą, że ten Żyd umarł z piątku na sobotę, aby jakiego kłopotu ubogi człowiek nie miał od żony i od potomków tegoż Żyda, prosił prawa, aby dopuścili inkwizycji wywieść i onej wysłuchać (z jakiej przyczyny ten Żyd umarł). A wysłuchawszy onej, porządnie według prawa magdeburskiego wydać raczyli.

Et judicium praesens scabinale Biecense affectationi personaliter instantis Iwani Boyko annuente ad inquisitionem testium hac in causa notitiam habentium mediante judicii sui sententia processis. 
Sub eodem actu

Comparens personaliter coram judicio et actis praesentibus scabinalibus Biecensibus famatus Albertus Pieczek civis et dealbator Bieczensis -- [268v] Przyjechał tu do miasta Żyd Rubin Josefowicz i przyszedł do mnie, pytając mię o płótna, jeśliby mógł dostać kędy kupić. Potem poszedł z panem Iwanem Greczynem do mnie i wstąpili do pani Pląszowskiey. Jam też za nimi poszedł i pili tam piwo i wino. Potem w wieczór poszedł na blich i tam spał. Nazajutrz mówiła mu czeladź, żeby się nie bawił na blechu, powiadając mu, że tu Żydowi nie godzi się u nas długo bawić według praw i przywilejów. Poszedł z blechu, a pan Iwan Boyko mówił mu, aby wsiadał, ponieważ towar swój (skrzynka płótna) dał na sanie jego. Ten Żyd rzekł: „Jedzcie wy, a ja was dogonię”. Wstąpił potem do pana Woyciecha Pieczka — pana brata mego rodzonego. I tam kazał sobie dać gorzałki i pił, jako słyszał, i dworską czeladź częstował, która [269] nie chciała pic, a on sam pił. Poszedł potem wieczorem na blech, pijany będąc, bom go potkał w bramie i położywszy się usnął i tak do tego czasu śpię. --

\section{Sub eodem actu}

Comparens personaliter coram judicio et actis praesentibus scabinalibus Biecensibus honoratus Albertus Kędziersky consul residens civitatis Biecensis -- Przyszedł do mnie w piątek Żyd Rubin Josefowicz z kupczykiem (nie znam go) i powiedział mi strony płótna, które u mnie PP. Grekowi byli potargowali i talar mi byli zadali, że z tego targu nic, bo się dosyć nakupili i pieniędzy im nie stało. Jam go chciał wódką poczęstować, ale nie chciał pic, raz tylko skosztowawszy powiedział, żem się wczoraj u p. Pleszewskiey zabawił i podpiłem sobie na winie i je- [269v] szcze w głowie czuję. Rzekł mi potem: „Będę ja tu za dwie niedzieli, jeżeli WMc płótna swego nie sprzedasz, kupię go ja u WMci”. Poszedł potem ode mnie, ale nie wiem kędy. Aż w sam wieczór dobry usłyszałem, że straż nocna rozgłosiła, że Żyd (ten, który tu przyjechał) będąc żyw w dzień, teraz mrokiem na blechu umarł. Jam się temu dziwował i nie wierzyłem temu. Nazajutrz w sobotę lepiej usłyszałem, że Żyd na blechu umarł wczoraj, o czym Grzegorz adstant z Wieliczki, który tu był w Mięsopusty i dialog wyprawiał, powiedział mi, że dnia wczorajszego był u pana bakałarza pijany bardzo i prosił mię pan bakałarz, abym go na blech zaprowadziłem, który położywszy się, zaraz usnął, a jam poszedł do miasta. --

\section{Sub eodem actu}

Comparens personaliter coram judicio et actis praesentibus scabinalibus Biecensibus laboriosus Simon Stenclowicz auriga dealbatorii civilis -- [270] Nie byłem na ten czas na blechu, bom do lasu jeździł, kiedy kupcy na blechu stanęli we czwartek, którzy na płótna przyjechali. Przyjechawszy w wieczór, pytałem się, co by to za ludzie byli i kto im tu kazał 
wjechać. Powiedzieli, że pan blicharz. Nazajutrz w piątek przyszedł pan Pieczek i rozkazał mi, abym mówił Żydowi, żeby się na blechu nie bawił. Powiedziałem Żydowi o tym. Żyd, wziąwszy swój tłumoczek, poszedł z blechu. Jam też przez cały dzień nawóz woził na ogród pani Peickowiy. Nie wiem, kędy się Żyd przez cały dzień bawił. Przyjechałem wieczorem na blech, aż mi powiedzą, że tu Żyd umarł, który wczoraj nocował, przyprowadzili go bardzo pijanego. --

Sub eodem actu

Comparens personaliter coram judicio et actis praesentibus scabinalibus Biecensibus famatus Martinus Kozik cechmagister contubernii lanionum civis Biecensis -- [270v] W piątek przed wieczorem jechałem w potrzebie swojej do Jasła i [s]potkałem tych kupców na drodze pod klasztorem, którzy tu byli dla płócien przyjechali, i rzekłem do Pana Iwana: „Już to WMc od nas jedziecie”. Odpowiedział: „Dosyć my się tu namieszkali”. A było ich czworo sani. Jam rzekł: „Jedźcie WMc, bo ja też jadę w jedną drogę”. Rzekli mi: „Musimy czekać tego Żyda, który z nami przyjechał, który się zapił bardzo”. Jam rzekł: „Słusznie go poczekać, ponieważ pospołu z WMi przyjechał”. Ja pojechałem, a oni też za mną się ruszyli, i przyjechawszy do Siepietnicy ku karczmie, chcieli stanąć, ale im powiedziała karczmarka, iż tu nie masz ani piwa, ani owsa, nie będziecie tu mieć żadnej wygody. Potem porwawszy się, pojechali na Serwoniec. Jam się obrócił na Lisowsk do Jasła, a oni gościńcem zwyczajnym jechali. --

Sub eodem actu

Comparens personaliter coram judicio et actis praesentibus scabi- [271] nalibus Biecensibus famatus Valentinus Kozdry Cechmagister contubernii sartorum civis Biecensis -W dzień piątkowy potknąłem się z Żydem w Rynku, który tu do blichu dla płócien przyjechał, którego jam znał na jarmarkach i kupował u naszych płótna. Prosiłem go do siebie w dom i częstowałem go według znajomości gorzałką. Który napiwszy się raz i drugi i obaczywszy u mnie na stole mięsopustni jeszcze potrawy, naparł się ich. I dałem mu pieczeń i ser świeży na pierogi. Który wziąwszy te rzeczy i włożywszy w koszałkę, poszedł ode mnie i słyszałem, że był u P. Pieczka, kędy kazał sobie dać kwartę gorzałki. I pił, i był pijany bardzo. Nazajutrz powiedziano, że Żyd na blechu umarł. --

Sub eodem actu

Comparens personaliter coram judicio et actis praesentibus scabinal- [271v] ibus Biecensibus honoratus Albertus Piecek consul residens civis Biecensis -- Przyszedł do mnie w dzień piątkowy Żyd, który tu dla płócien do Biecza przyjechał, którego jam przedtem nie znał. 
A jam na ratusz miał iść i pytałem go, czego by potrzebował. Powiedział: „Oto tego pana szukam,” - pokazał na Jana Baptystę, którego u mnie zastał i częstowali go goście gorzałką, którzy u mnie na ten czas byli. W tym kazał sobie dać kwartę gorzałki, ale mu pani nie chciała dać, mówiąc: „Coć ${ }^{14}$ po niej”. I gdy drugi raz i trzeci prosił, aby mu gorzałki dano, kazała mu kwartę gorzałki przynieść, której ze trzy kieliszki sam kwaterkowe wypił, a drugą [z] szkolnymi, którzy byli po wizycie przyszli, wyczęstował. Poszedł potem ode mnie i dobrze z chodu szedł, jako mi powiedziano, bom ja na ratuszu był na ten czas. --

Sub eodem actu

Comparens personaliter coram judicio et actis praesentibus scabinalibus Biecensibus honesta Dorothaea laboriosi [272] Simonis Stenclowicz aurigae civilis Biecense consors -- W piątek po zapustnych dniach przed wieczorem przyprowadził jakiś młody człowiek, którego ja nie znam, Żyda pijanego na blich i posadził go podle pieca. I upominał mu się na garniec miodu, który począł szczypać się ${ }^{15}$, ale nie dał nic. I położywszy się na ławie usnuł, a potem z lawy spadł na ziemie i począ chrapać. Przyszli Rusinowie, którzy z nim byli, i budzili go dwa razy, ale iż bardzo pijany był, musieli mu dać pokój i odeszli. A my też dwie białogłowy, którzy my w ten czas na blichu w izbie były, nie wiedziałyśmy, co z tym było czynić. A ci Rusinowie, odchodząc, prosili nas, abyśmy powiedzieli Żydowi, kiedy się obudzi, aby sobie konia najął, bo go za milę będziemy czekać i zapłacimy od konia. -- $[272 v]$

Sub eodem actu

Comparens personaliter coram judicio et actis praesentibus scabinalibus Biecensibus honesta Haedvigis laboriosi Christophori Bielanowicz dealbatoris Biecensis consors -Przyprowadził Żyda bardzo pijanego, który na nogach nie mógł stać, człowiek młody, ale nie znam go, na blech w piątek przed wieczorem. I posadził go na ławie podle pieca, który wspierał się na piecu, zemknął się potem na ziemie i leżał na wznak. My, białogłowy, którzy my były na blechu, bo mężów naszych w domu nie było, bo nawóz wozili aż do wieczora, mówiłyśmy temu, który tego Żyda przyprowadził: „Weźcie go stąd, bo nam tu nic po nim”. Rzekł: „Ja go na sobie nie poniosę”. Przyszedł potem ten Rusin, który tu jest, samotrzeć i widząc go bardzo pijanego, mówił te słowa: „O nieszczęśliwe pijaństwo! Do czego ludzi prowadzi”. I prosił nas, aby tu leżał, aż by się otrzeźwił. Przyszedł [273] potem i drugi raz, a widząc, że Żyd nie mógł się obaczyć, bo spał i chrapał, prosił nas bardzo,

14 "coć" could be compared with "co". See: Stownik Staropolski, ed. Stanisław Urbańczyk, tom 1, A-Ć (Warszawa: Zakład im. Ossolińskich, 1953-1955), 326.

15 In the original text (not modernised): "począł się szczypłać". 
żeby się tam przespał, a kiedy się ocucę, żebyś my mu powiedzieli, żeby sobie konia najął i saneczki, i przyjechał za nami, bo go za milę będziemy w karczmie czekać. Przyszły dwie panie na blech do magla (pani Olszowska i pani Leszczynska) i, obaczywszy Żyda [na] wznak leżącego, poczęły mówić: „Pewnie ten Żyd umrze”. My, wyprowadzając ich z izby, wyszłyśmy do sieni. Weszłyśmy potem do izby i spojrzałyśmy na Żyda, a już Żyd umarł - zbielał jako kreda. Chciałyśmy mu piwa zagrzać, żebyśmy go napoiły, i nim my piwa zgrzały aż Żyd bez pary. --

Idem Ioan Boyko sub eodem actu superiori

Post insertam inqvisitionem idem Ioan Boyko civis Białocerkviensis commonstravit in eadem [273v] actione rellationem providi Valentini Mołtaga generalis regni coram actis castrensibus Biecensibus ${ }^{16}$ recognitam et ex iisdem actis sub sigillo autentice extraditam petens illam actis praesentibus suscipi cuius tenor talis est.

Actum in castro Biecensi feria secunda post dominicam Invocavit Quadragesimalem proxima Anno Domini Millesimo sexcentessimo sexagesimo tertio ${ }^{17}$.

Woźny koronny generał, opatrzny Walenty Mołtaga z Skalmierza przed urzędem i aktami grodzkimi bieckimi obecnie stojąc, dobrowolnie a wyraźnie zeznał, iż za rekwizycją gospodarza blechowego bieckiego w sobotę blisko przeszłą z miasta Biecza na blich pod miastem leżący zstąpił. I tam trupa niewiernego niegdyś Rubina Josefowicza z Brodów, z piątku na sobotę przeszłą nie wiedząc z jakiej przyczyny nagle (tamże na blechu) zmarłego, widział i oglądał. Na którym żadnego razu i znaku pobicia albo gwałtu nie widział a nim [274] mógł uznać. Co, iż tak, a nie inaczej jest - prawdziwie zeznał. --

\section{Idem Ioan Boyko de Biała Cerkiew \\ Sub eodem actu nullitatis}

Coram eodem officio famatus Ioan Boyko civis Białocerkviensis prezentował inkwizycję autentyczną z ksiąg miejskich bieckich wydaną; przy tym i relację generała koronnego opatrznego Walentego Mołtaga, także też autentyczne z akt grodzkich bieckich pomienionemu Iwanowi Boykowi wydaną. A to ratione zejścia z tego świata Rubina Josefowicza Żyda obywatela ${ }^{18}$ brodzkiego z nim będącego w mieście Bieczu. Do której przesłuchanie inkwizycji przypozwał Hesterke zonę nieboszczyka Rubina. A przy niej, stanąwszy opatrzny Chyl Moszkowicz mieszczanin Brodzki i Josef Lewkowicz, krewni jej inkwizycję dostateczną od wielu osób godnych o śmierci onego zeznających wysłuchawszy i wyrozumiawszy,

\footnotetext{
16 The scribe wrote "Buscensibu" but later corrected it to "Biecensibus".

17 12th of February 1663.

18 The scribe wrote "Mieszczanina", but later corrected it.
} 
dobrze także znając, zdają wszelaką uczciwość i przystojne się z ludźmi za- [274v] chowanie Iwanowe. Stąd nie będąc żadnego porozumienia a nim [być] przyczyną śmierci Rubina przyrzeczonego Iwana Boyka i niewinnym przyznali, nie impedować wiecznymi czasy submitowali się dobrowolne i dobrze porządnie. --

Source: CSHAU in Lviv. Collection 24. Inventory 1. File 13. P. 266v.-274v.

\section{BIBLIOGRAPHY}

Central State Historical Archive of Ukraine in Lviv city. Collection 24. Inventory 1. Folders 1, 13, 33.

Jaworski Franciszek, 'Brody’, Tydzień: Dodatek literacko-naukowy "Kuriera Lwowskiego” (15 lutego 1903).

Kravčenko Volodimir, Âkovenko Nataliâ, Torbivlâ na Ukraïni XIV - ser. XVII st.: Voliń i Naddniprânsinina (Kiï: Naukova Dumka, 1990).

Lepszy Kazimierz, Instrukcja wydawnicza dla źródet historycznych od XVI do potowy XIX wieku (Wrocław: Zakład im. Ossolińskich, 1953).

Ślawski Tadeusz, Biecz i Gorlice: ośrodki handlu winem od XIV w. do XVIII w. (Biecz: Towarzystwo Kulturalne Biecza i Regionu im. Marcina Kromera, 2001).

Ślawski Tadeusz, Produkcja i wymiana towarowa Biecza w XVI i XVII wieku. (Rzeszów: Towarzystwo Przyjaciół Nauk w Przemyślu, 1968).

Ślawski Tadeusz, 'Studia nad ludnością Biecza w wiekach XVI-XVII', Matopolskie Studia Historyczne 1, zeszyt 3-4 (1958), 21-66.

Povsâkdennâ ranńomodernoï Ukraïni., ed. Viktor Horobeć, tom 1, Praktiki, kazusi ta deviaciï povsâkdennâ (Kï̈: İnstitut İstoriï Ukraïni NAN Ukraïni, 2012).

Povsâkdennâ ranńomodernoï Ukraïni ed. Viktor Horobeć, tom 2, Svit rečej i povsâkdennih uâvleń (Kiï: İnstitut İstorii Ukraïni NAN Ukraïni, 2013). Ukraïnśke povsâkdennâ ranńomodernoï dobi: zbirnik dokumentiv, ed. Irina Vorončuk, Vipusk 1, Voliń 16 st. (Kiïv: Feniks, 2014).

Wurm Dawid, Z dziejów żydostwa Brodzkiego za czasów dawnej Rzeczypospolitej Polskiej (do r. 1772) (Brody: Z drukarni Pitscha i Weinstocka, 1935). 